\title{
Sequential approach of internal maxillary- to-middle cerebral artery bypass and endovascular occlusion for giant middle cerebral artery aneurysm: a case report
}

\author{
Andrey Vladimirovich Sergeev ${ }^{1 *}$ (D) Alexander Viktorovich Savello², Vladislav Urievich Cherebillo²,
} Aigazi Islamovich Kiskaev ${ }^{2}$ and Fatima Chemurzieva ${ }^{2}$

\begin{abstract}
Background: The combined approach to complex brain MCA aneurysm seems to be generally considered viable. Although it is fairly common, the combinations of modalities, which are suggested in different case reports, vary significantly. This case discusses a sequential approach of reconstructive microsurgery with internal maxillary-tomiddle cerebral artery bypass followed by the balloon test occlusion and endovascular embolization of the aneurysm and the MCA. The combined approach together with use of maxillary artery helped minimize the intraoperative and postoperative complications.

Case presentation: A 62-year-old female with rare episodes of headache and depression revealed giant middle cerebral artery aneurysm. The patient underwent a combined operation in a hybrid operating room with no serious neurologic deficit after surgery.

Conclusions: Multimodality management in a hybrid operating room should be considered in case of complex fusiform aneurysm of MCA, which is associated with high risks of clipping. Thus, the sequential procedures will improve patient outcomes in treatment of complex MCA aneurysms.
\end{abstract}

Keywords: Combined approach, Endovascular occlusion, A giant aneurysm

\section{Background}

In the past few years, we have witnessed combined approach taking a leading role in the management of complex aneurysm after conventional therapy with a single modality had failed. Complex cases of the middle cerebral artery (MCA) aneurysm are the best example of an aneurysm for which either approach rather than a combined one is an unlikely solution.

The combined approach is preferable due to the following features of the complex MCA aneurysm: a very broad neck (dome-to-neck ratio $<1.5$ ); the absence of a

\footnotetext{
*Correspondence: md_sergeev@yahoo.com

${ }^{1}$ Neurosurgery Department of Almazov National Medical Research Centre, Saint Petersburg, Russia

Full list of author information is available at the end of the article
}

neck, such as in fusiform aneurysms or saccularfusiform aneurysms; the presence of severe atherosclerosis or calcification in the neck area; the presence of extensive thrombosis inside the aneurysm; the origin of critical branches from the aneurysm sac or neck; symptomatic dissecting aneurysms; and small blister aneurysms that have no neck at all [1].

\section{Case presentation}

\section{Patient Information}

A 62-year-old right-handed woman suffered from virus meningoencephalitis when she was 15 years old. Subsequently, she had 15 min night panic attacks with hallucinations, hemihypesthesia without seizures. This paroxysm stopped in 5 years with no treatment. In 2015

\section{Springer Open}

(ㅇ The Author(s). 2021 Open Access This article is licensed under a Creative Commons Attribution 4.0 International License, which permits use, sharing, adaptation, distribution and reproduction in any medium or format, as long as you give appropriate credit to the original author(s) and the source, provide a link to the Creative Commons licence, and indicate if changes were made. The images or other third party material in this article are included in the article's Creative Commons licence, unless indicated otherwise in a credit line to the material. If material is not included in the article's Creative Commons licence and your intended use is not permitted by statutory regulation or exceeds the permitted use, you will need to obtain permission directly from the copyright holder. To view a copy of this licence, visit http://creativecommons.org/licenses/by/4.0/. 
MR tomography, MR angiography showed right basal ganglion atrophy and 2 aneurysms of the right MCA. The patient underwent endovascular operation of M1 segment in 2015 at another medical center. Recently, she has had rare episodes of headache and depression; therefore, she received counseling with a psychotherapist and has taken carbamazepine $400 \mathrm{mg}$ a day. She has no serious neurologic deficit.

\section{Imaging studies}

Computed tomography (CT) angiography and magnetic resonance imaging (MRI) conducted at our neurosurgical center revealed a big partial thrombosed fusiform M1 segment aneurysm of the right MCA $(15 \times 12.5 \times$ $17.5 \mathrm{~mm}$ ) and a small saccular aneurysm of the anterior temporal artery $(5 \times 4 \times 4 \mathrm{~mm})$, which was endovascularly occluded (Figs. 1 and 2).

\section{Surgical findings}

Preoperative diagnostic Matas test revealed a reversible weakness in the left arm and leg for $5 \mathrm{~min}$, which confirmed the insufficient collateral blood flow ruling out the possibility of a destructive operation. For this reason, we decided to apply a bypass anastomosis and then perform endovascular occlusion of the MCA and aneurysm.

The operation was conducted in the hybrid operating room equipped with intraoperative angiography and flat panel CT-perfusion (Artis zeego, Siemens Healthineers, Forchheim, Germany). Firstly, a pterional craniotomy with resection of the zygomatic arch was performed to facilitate retraction of the temporalis muscle to the lower part. The internal maxillary artery (IMaxA) was exposed in the pterygopalatine fossa. The proximal IMaxA was then secured with a temporary clip, and the distal end divided with ligation. An end-to-end anastomosis was

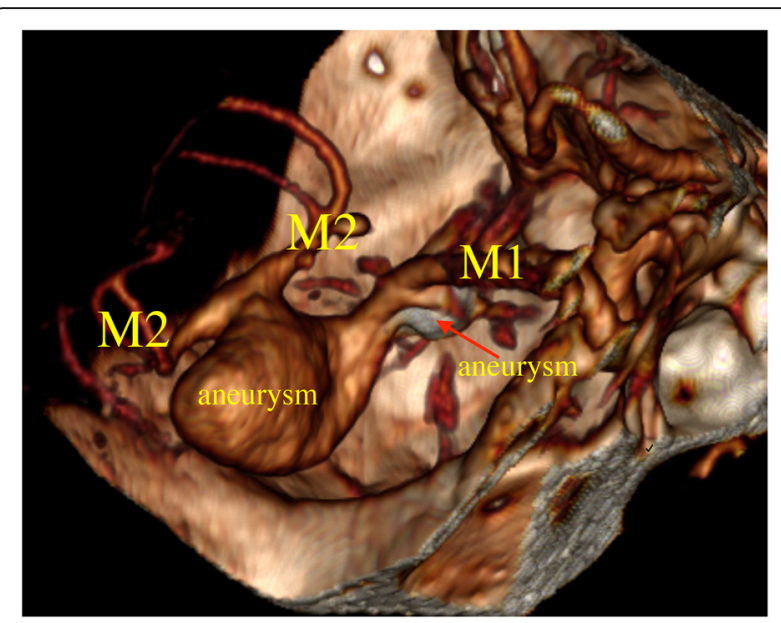

Fig. 2 CT angiography showed a fusiform aneurysm in M1 segment of the right MCA

applied connecting the radial artery graft and the proximal segment of the MA. The distal end of the donor graft was then anastomosed with M2 segment of the right MCA. Within 2 postoperative days, there were no neurological complications. The CT angiography showed a good patency of the bypass (Fig. 3).

\section{Postoperative course}

After a 2-day observation, we executed the conventional MCA occlusion with a balloon tip catheter and assessment of neurological condition for $10 \mathrm{~min}$ (Fig. 4).

Meanwhile, the CT perfusion test with cerebral blood volume (CBV) assessment was conducted to reveal the possible ischemic damage to the brain [2] (Fig. 5). Over this time, no neurological complications were detected.

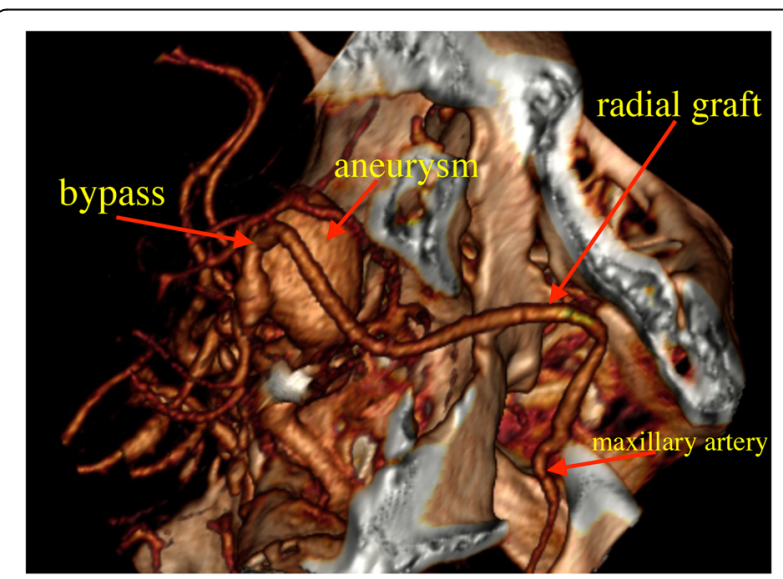

Fig. 3 CT angiography showed a good patency of the bypass
Fig. $1 \mathrm{MRI}$ revealed a giant fusiform thrombosed aneurysm in M segment of the right MCA

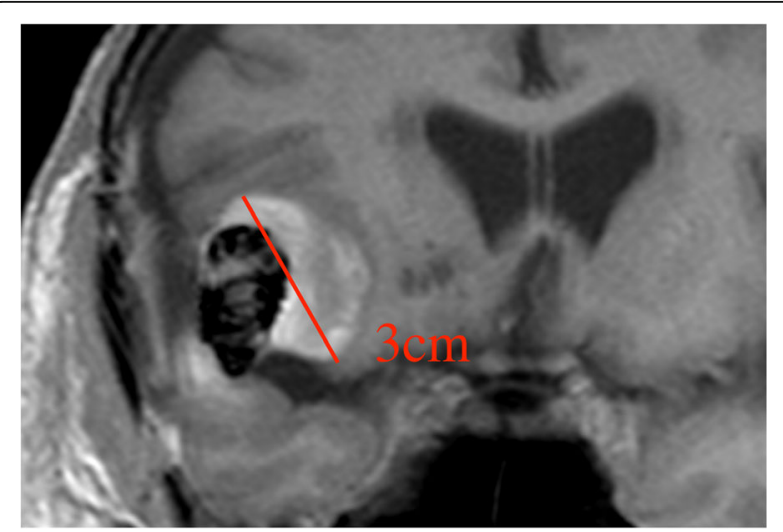




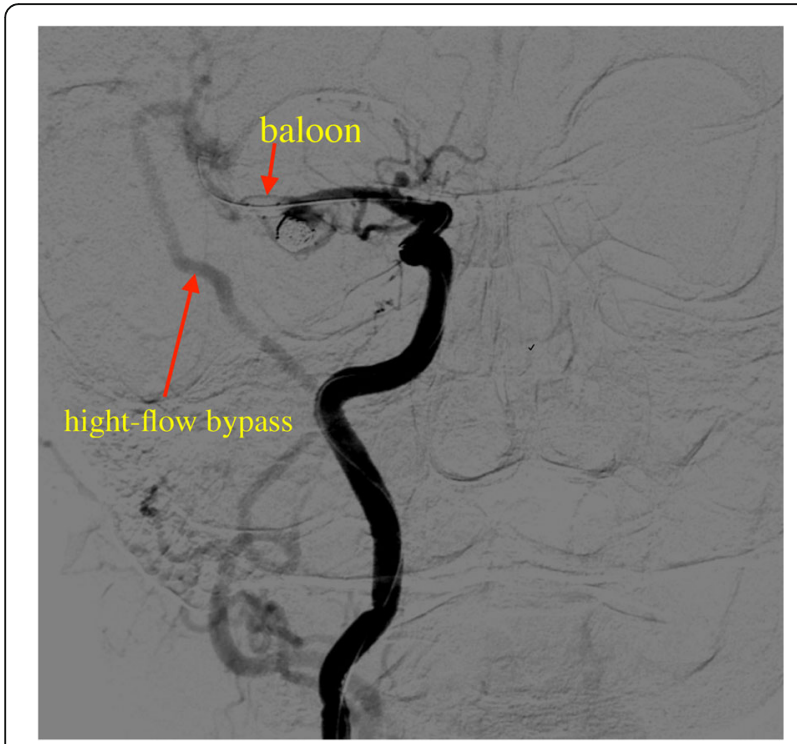

Fig. 4 Balloon test occlusion with good potency of the IMaxA-to-MCA bypass

There was a good graft blood supply of the temporal, parietal, and frontal branches during the MCA occlusion, which was identified by the cerebral angiography. Finally, the proximal part of the aneurysm and the parent MCA artery were successfully occluded with platinum spiral coils (Figs. 6 and 7). The patient received 3000 units of heparin intravenously during endovascular procedures.

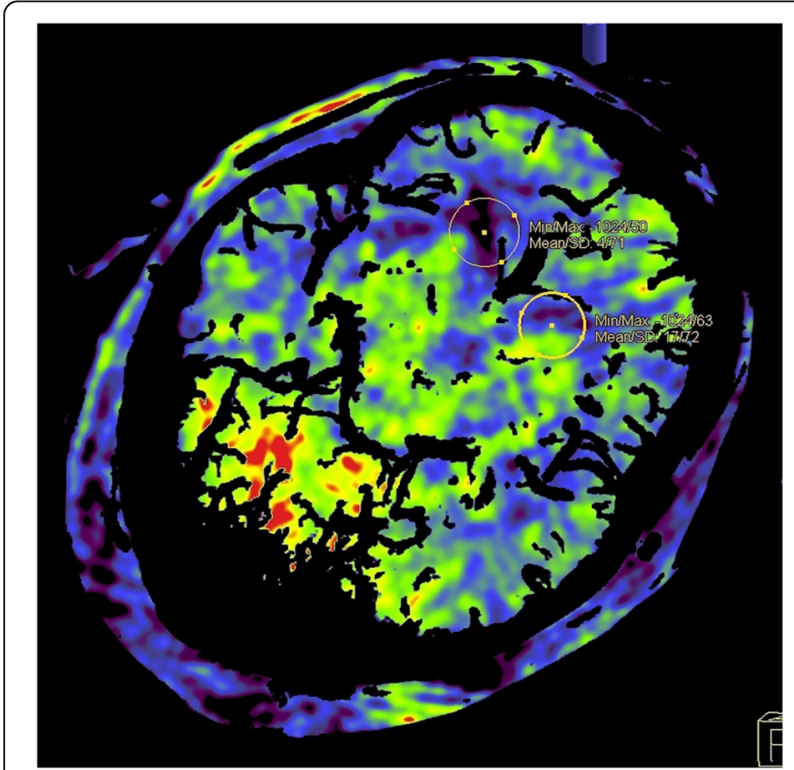

Fig. 5 Flat panel CT perfusion (CBV) showed no perfusion differences between brain hemispheres

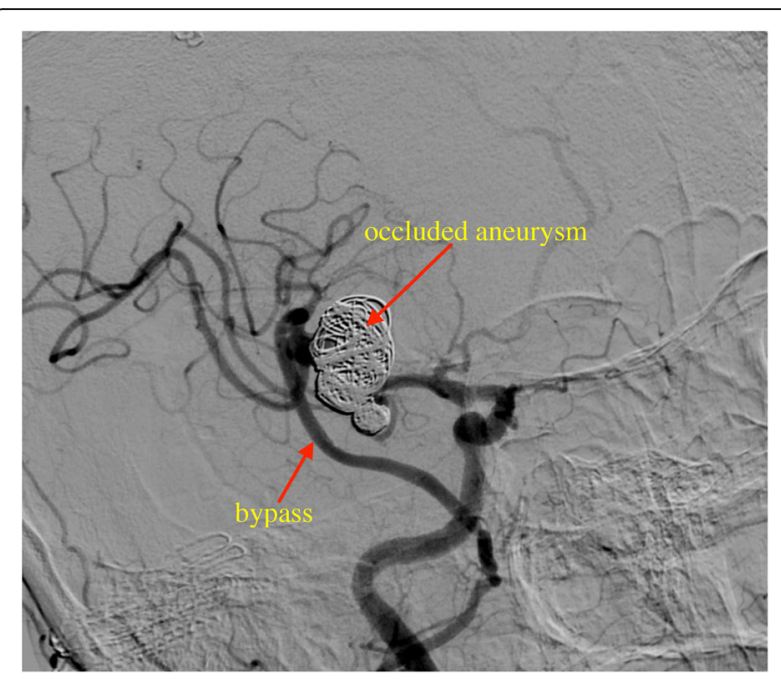

Fig. 6 Cerebral angiography showed MCA occlusion and a good graft blood supply. Sagittal projection

Postoperative MRI angiography revealed a total aneurysm occlusion and good filling of distal MCA branches maintained by the bypass (Fig. 8).

The patient recovered quickly without any neurological deterioration and was discharged home in good condition in 10 days.

\section{Discussion}

The preoperative Matas occlusion test confirmed that a destructive operation was impossible. The fusiform structure of the aneurysm as well as the origin angle of

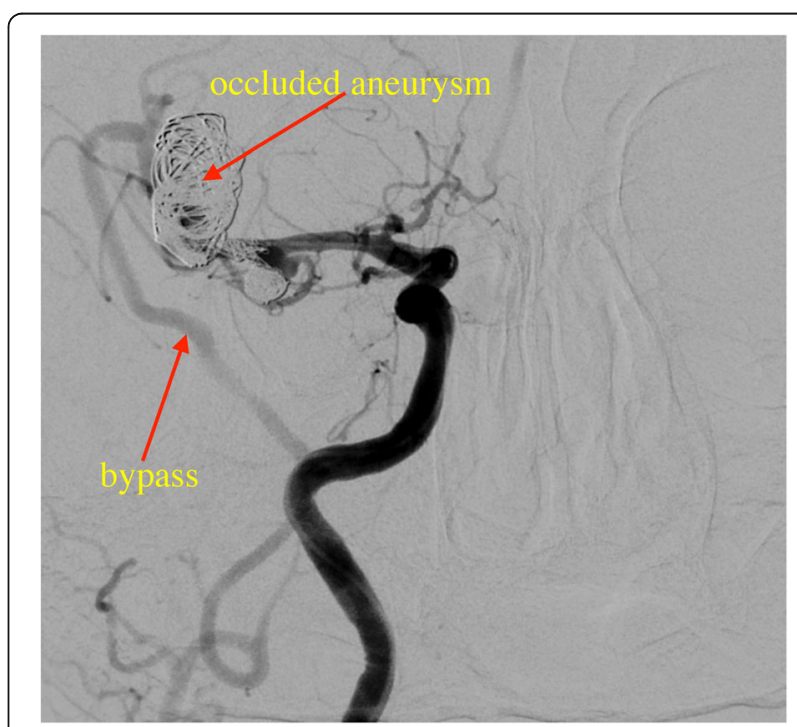

Fig. $7 \mathrm{MRI}$ cerebral angiography showed MCA occlusion and a good graft blood supply. Frontal projection 


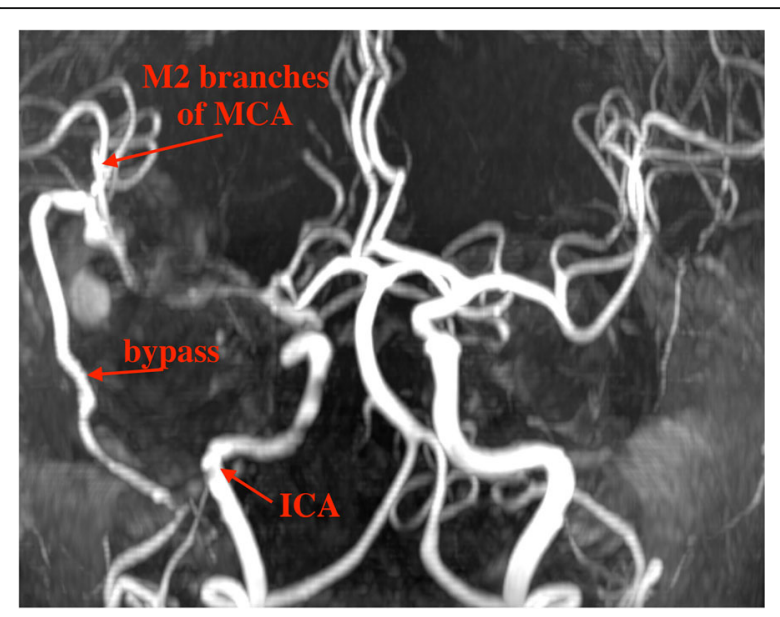

Fig. $8 \mathrm{MRI}$ angiography revealed a total aneurysm occlusion and good filling of distal MCA branches

M2 MCA segments did not allow for a flow diverter stent [3]. Indeed, the chosen approach is complex but less risky, while endovascular stenting is less complex but more risky. According to case reporters and a cohort study, flow diverters in giant aneurysms are associated with higher risks of thrombosis and recurrences (20\%) [4-6]. This is even more likely for MCA with perforating branches. In view of the planned occlusion of the MCA supplying the aneurysm, we were to choose the suitable bypass that would substitute for the MCA. The fusiform structure, giant size, and partial thrombosis of the aneurysm does not allow for its clipping. Thus, the conventional bypass, such as low flow extracranial-to-intracranial (EC-IC) bypass of the superior temporal artery, was rejected because of the minor diameter of the given artery in the patient and therefore insufficient blood flow. The only option left was a high flow bypass [7-9]. Out of the two types of high flow bypass, we decided on the IMaxAto-MCA bypass which has a number of advantages over the conventional EC-IC bypass. These advantages include the following: shorter graft length, avoidance of a cervical carotid artery dissection and its attendant complications, a microsurgical view of the entirety of the intracranial graft and both the proximal and distal anastomoses within the same field, and minimization of the risk of graft kinking and compression. These benefits are highlighted in cadaveric and radiological studies aimed to define the IMaxA anatomy, illustrate a novel method for harvesting, and prepare it for extracranial-to-intracranial bypass [1013]. Several recent articles discussed good outcomes of IMaxA to MCA bypass in patients with different complex aneurysms [14-17].
Out of two ways of occlusion, namely, the microsurgical and the endovascular occlusions, the latter is preferable due to a number of advantages. The former approach requires additional microsurgical dissection of a big fusiform aneurysm, which raises a risk of brain damage. Moreover, microsurgical procedure involves somatosensory and motor evoked potentials monitoring, which results in significant false-negative rates and inconsistencies because of patient unconsciousness [18, 19]. By contrast, endovascular occlusion is not conducted in one go, which means that balloon test occlusion (BTO) is utilized before the occlusion of MCA. Since 1974, BTO has been used for major cervical and intracranial vessels $[20,21]$. This allows for assessment of the ischemic deficits while the patient is awake. Besides, there are good possibilities to visualize bypass potency in angiographic pictures. In his research, Lawton at al. proved the efficacy of BTO in combined operations on complex aneurysms [3]. It is worth noting that the time spell between bypass surgery and endovascular aneurysm occlusion should be $48-72 \mathrm{~h}$ to confirm the absence of bypass thrombosis and give time for the anastomose endothelialization $[22,23]$.

\section{Conclusion}

This combination of MA-MCA bypass with subsequent BTO and endovascular embolization of a complex MCA aneurysm has not been reviewed in medical studies. Multimodality management in a hybrid operating room should be considered a welcome addition that will improve patient outcomes in treatment of complex aneurysms.

\section{Abbreviations \\ MCA: Middle cerebral artery; IMaxA: Internal maxillary artery; EC- \\ IC: Extracranial-to-intracranial; CBF: Cerebral blood volume; CT: Computed} tomography; MRI: Magnetic resonance imaging; BTO: Balloon test occlusion

\section{Acknowledgements \\ Not applicable}

\section{Authors' contributions}

AS performed the operation, analyzed the literature, and wrote the text of the article. AVS performed the operation and made design of the work. VCh made substantial contributions to the conception of the operation. AK took part in the operation. FCh participated in writing and translation the text of the article. All authors have read and approved the manuscript.

\section{Funding}

None

\section{Availability of data and materials} Not applicable

Ethics approval and consent to participate Not applicable

Consent for publication

Received from patient in writing form 


\section{Competing interests}

No competing interest

\section{Author details}

${ }^{1}$ Neurosurgery Department of Almazov National Medical Research Centre, Saint Petersburg, Russia. ${ }^{2}$ National Medical Research Centre, Saint Petersburg, Russia.

Received: 16 April 2020 Accepted: 15 February 2021

Published online: 04 March 2021

\section{References}

1. Sekhar LN, Natarjan SK, Ellenbogen RG, et al. Cerebral revascularization for ischemia, aneurysms and cranial base tumor. Neurosurgery. 2008;62(6):1373410.

2. Struffert T, Deuerling-Zheng Y, Engelhorn T, et al. Feasibility of cerebral blood volume mapping by flat panel detector $C T$ in the angiography suite: first experience in patients with acute middle cerebral artery occlusions. AJNR Am J Neuroradiol. 2012;33:618-25

3. Michael TL, Alfredo QH, Nader SBS, Junaid YMBS, Christopher FD. Combined microsurgical and endovascular management of complex intracranial aneurysms. J Neurosurg. 2003;52:263-75.

4. Sack J, Cheung V, Amaro D, Wali AR, Santiago-Dieppa DR, Pannell JS, Khalessi AA. World Neurosurg. 2017;103:348-54.

5. Krishna C, Sonig A, Natarajan SK, Siddiqui AH. The expanding realm of endovascular neurosurgery: flow diversion for cerebral aneurysm management. Methodist Debakey Cardiovasc J. 2014;10(4):214-9.

6. McDougall CG, Spetzler RF, Zabramski JM, et al. The barrow ruptured aneurysm trial. J Neurosurg. 2012;116(1):135-44.

7. Jafar JJ, Russell SM, Woo HH. Treatment of giant intracranial aneurysms with saphenous vein extracranial-to-intracranial bypass grafting: indications, operative technique, and results in 29 patients. Neurosurgery. 2002;51:138-44

8. Patel HC, Teo M, Higgins N, Kirkpatrick PJ. High flow extra-cranial to intracranial bypass for complex internal carotid aneurysms. Br J Neurosurg. 2010; 24(2):173-8

9. Ramanathan D, Temkin N, Kim LJ, Ghodke B, Sekhar LN. Cerebral bypasses for complex aneurysms and tumors: long-term results and graft management strategies. Neurosurgery. 2012;70(6):1442-57.

10. Abdulrauf SI, Sweeney JM, Mohan YS, Palejwala SK. Short segment interna maxillary artery to middle cerebral artery bypass: a novel technique for extracranial- to-intracranial bypass. Neurosurgery. 2011;68(3):804-8.

11. Eller JL, Sasaki-Adams D, Sweeney JM, Abdulrauf SI. Localization of the internal maxillary artery for extracranial-to-intracranial bypass through the middle cranial fossa: a cadaveric study. J Neurol Surg B Skull Base. 2012; 73(1):48-53.

12. Karabulut AK, Ustün ME, Uysal II, Salbacak A. Saphenous vein graft for bypass of the maxillary to supraclinoid internal carotid artery: an anatomical short study. Ann Vasc Surg. 2001;15(5):548-52.

13. Ulku CH, Ustun ME, Buyukmumcu M, Cicekcibasi AE, Ziylan T. Radial artery graft for bypass of the maxillary to proximal posterior cerebral artery: an anatomical and technical study. Acta Otolaryngol. 2004;124(7):858-62.

14. Shi $X$, Qian H, Singh KC, Zhang Y, Zhou Z, Sun Y. Bypass of the maxillary to proximal middle cerebral artery or proximal posterior cerebral artery with radial artery graft. Acta Neurochir. 2011;153:1649-55.

15. Wang L, Shi X, Qian H. Flow reversal bypass surgery: a treatment option for giant serpentine and dolichoectatic aneurysms-internal maxillary artery bypass with an interposed radial artery graft followed by parent artery occlusion. Neurosurg Rev. 2017;40:319-28.

16. Yu Z, Shi X, Qian $H$, et al. Internal maxillary artery to intracranial artery bypass: a case series of 31 patients with chronic internal carotid/middle cerebral arterial-sclerotic steno-occlusive disease. Neurol Res. 2016;38:420-8.

17. Wang L, Lu S, Qian H, Shi X'e. Internal maxillary artery bypass with radial artery graft treatment of giant intracranial aneurysms. World Neurosurg. 2017;105:568-84

18. Irie T, Yoshitani K, Ohnishi Y, et al. The efficacy of motor-evoked potentials on cerebral aneurysm surgery and new-onset postoperative motor deficits. J Neurosurg Anesthesiol. 2010;22:247-51.

19. Weinzierl MR, Reinacher P, Gilsbach JM, Rohde V. Combined motor and somatosensory evoked potentials for intraoperative monitoring: intra- and postoperative data in a series of 69 operations. Neurosurg Rev 2007:30:109-16.

20. Serbinenko FA. Balloon occlusion of saccular aneurysms of cerebral arteries. Vopr Neirokhir. 1974;4:8-15.

21. Serbinenko FA. Balloon catheterization and occlusion of major cerebral vessels. J Neurosurg. 2007;107(3):684-705.

22. Cooley BC, Li X, Dzwierzynski W, et al. The de-endothelialized rat carotid arterial graft: a versatile experimental model for the investigation of arterial thrombosis. Thromb Res. 1992:67:1-14.

23. Sigurbjornsson BJ, Hallberg E, Andren-Sandberg A, Ribbe E.

Endothelialization of anastomoses in the aorta and inferior vena cava of the rat. Microsurgery. 1994;15:787-94.

\section{Publisher's Note}

Springer Nature remains neutral with regard to jurisdictional claims in published maps and institutional affiliations.

\section{Submit your manuscript to a SpringerOpen ${ }^{\circ}$ journal and benefit from:}

- Convenient online submission

- Rigorous peer review

- Open access: articles freely available online

- High visibility within the field

- Retaining the copyright to your article

Submit your next manuscript at $\boldsymbol{\nabla}$ springeropen.com 